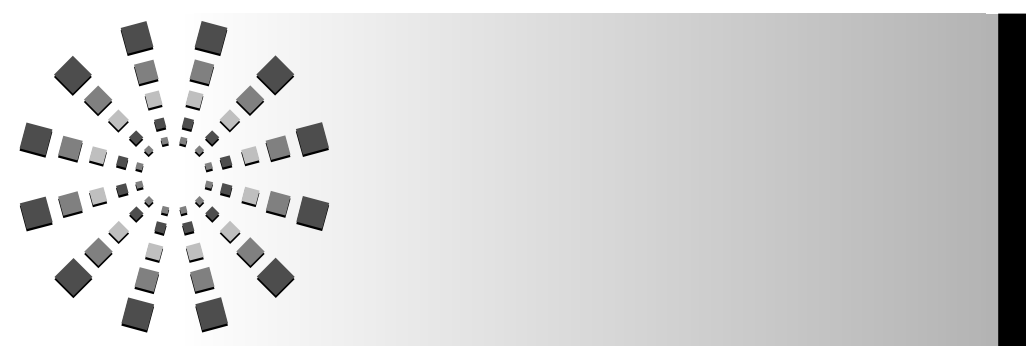

Li-Shan Ke, MSN, RN

Tai-Yuan Chiu, MD

Su-Shun Lo, MD

Wen-Yu Hu, PhD, RN

\title{
Knowledge, Attitudes, and Behavioral Intentions of Nurses Toward Providing Artificial Nutrition and Hydration for Terminal Cancer Patients in Taiwan
}

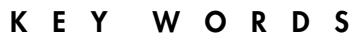

Artificial nutrition and hydration

Attitude

Behavioral intention

Knowledge

Terminal cancer patients
The aim of this study was to understand present knowledge, attitudes, and behavioral intentions of clinical nurses providing artificial nutrition and hydration (ANH) for terminal cancer patients. Study subjects were composed of 197 nurses from the gastroenterology, general surgery, and intensive care units of Taipei Veterans General Hospital in Taiwan. Subjects were surveyed between April and June 2005 via self-developed structural questionnaires. Collected data were descriptively analyzed with SPSS 11.0 software. Nurses' knowledge about palliative care was high (accurate-answer rate, 96.75\%); knowledge about providing $\mathrm{ANH}$ for terminal cancer patients was lower (accurate-answer rate, 53.67\%). Although nurses' attitudes about providing ANH for terminal cancer patients viewed $\mathrm{ANH}$ as having more burdens (mean [SD], 14.12 [3.62]) than benefits (6.35 [2.19]), nurses' behavioral intentions still favored providing ANH (3.21 [0.95]). In subjective norms, "attending physicians and/or superiors" (45.3\%) and, secondarily, "patients" (38.4\%) were important influencing persons on nurses' support for $\mathrm{ANH}$. Other influencing factors were communication difficulties with patients and/or family members (3.40 [0.83]), staff disagreements (3.01 [0.78]), and fear of medical dispute (3.42 [0.95]). Study results suggest that reinforcing in-service education to enhance nurses' knowledge of providing $\mathrm{ANH}$ for terminal cancer patients and building up positive attitudes and behavioral intentions may strengthen nurses'
Authors' Affiliations: Department of Nursing, Taipei Veterans General Hospital (Ms Ke); College of Medicine, National Taiwan University, and Department of Family Medicine, National Taiwan University Hospital (Dr Chiu); College of Medicine, National Yang-Ming University, and Department of Surgery, Taipei Veterans General Hospital (Dr Lo); and School of Nursing, College of Medicine, National Taiwan University, and National Taiwan University Hospital, Taipei, Taiwan (Dr Hu).
Corresponding author: Wen-Yu Hu, PhD, RN, School of Nursing, College of Medicine, National Taiwan University, 1 Jen-Ai Rd, Sect 1, Jhongjheng District, Taipei 100, Taiwan, ROC (weyuhu@ha.mc.ntu.edu.tw).

Accepted for publication January 25, 2007. 


\section{efforts to actively communicate and cooperate with physicians in assisting patients and families to make the most appropriate medical decisions.}

I n Taiwan, cancer ranks first among the 10 leading causes of death. In 2004, a total of 133,679 deaths occurred from all causes. Of these, 36,357 people died of cancer, representing $27.20 \%$ of all deaths, or 1 in 4 deceased individuals. ${ }^{1}$ When cancer patients approach the terminal stage of the disease, they will often experience decreased appetite, anorexia, dysphagia, or other complications such as intestinal obstruction. These complications result in a decrease in oral intake ability, with subsequent weight loss and weakness. Artificial nutrition and hydration (ANH) is commonly viewed as having effects that may prolong patients' lives, increase patients' strength, and also improve awareness levels. ${ }^{2-5}$ In clinical practice, patients who are malnourished from lack of intake are often given major fluid replacement, peripheral parenteral nutrition, or even total parenteral nutrition., 2,6-13 Several studies suggest that excessive supply with fluid and nutrition may increase body loading and result in discomfort for terminally ill patients. ${ }^{14-24}$ A study by Morita et $\mathrm{al}^{25}$ pointed out that additional supplementation of $\mathrm{ANH}$ can not only cause limb edema or general edema in terminal cancer patients, it can also result in severe pleural effusion and pulmonary edema, with consequent dyspnea, and a decrease in patients' quality of life. In addition to this, Burge et $\mathrm{al}^{26}$ conducted a retrospective study of hospital records and found that as many as $81 \%$ of inpatients had intravenous catheters in their last month of life, and 69\% had intravenous catheters when they died. The title of the Burge article asked appropriately: "Intravenous Fluids and the Hospitalized Dying: A Medical Last Rite?” This also reminds us that, with the advancement of modern medicine, the final dignity in life is often neglected. If $\mathrm{ANH}$ is of no benefit to terminal cancer patients or is actually more harmful than beneficial, limited provision or no provision should be considered to prevent prolonging patients' suffering. The principle of palliative care, from an ethical perspective, focuses on maintaining a meaningful physical, psychological, and social existence in the patient and at the same time caring for their family members. $^{27}$ Providing ANH is not the only measure that satisfies the physiological needs of patients. However, most terminal cancer patients today are unable to be transferred to palliative care wards, ${ }^{28}$ and medical care is therefore provided in general wards or intensive care units. This situation may be inappropriate because medical personnel in general wards and intensive care units have different care beliefs than palliative unit staff about providing ANH. This directly reflects areas of insufficiency in Taiwanese nursing education regarding care for terminally ill patients. Hence, the main objective of this study was to explore the present state of knowledge, attitudes, and behavioral intentions among nurses from general wards and intensive care units toward providing ANH for terminal cancer patients. We hoped that the results of our study would provide useful reference data for the development of future university and workplace education, ultimately improving the quality of care for terminally ill patients.

\section{Methods}

\section{Subjects}

Eligibility criteria for this study included nurses from the gastroenterology, general surgery, and intensive care units of Taipei Veterans General Hospital, enrolling a total of 197 nurses. Using a questionnaire survey method, the self-developed structural questionnaire "Questionnaire on the Knowledge, Attitudes, and Behavioral Intentions of Medical personnel in Providing Artificial Nutrition and Hydration (ANH) for Terminal Cancer Patients" was used for data collection between April and June 2005. Before the study was conducted, the research plan was presented to an institutional review board of Taipei Veterans General Hospital, where the study was to take place. After evaluation and approval, the study was formally initiated.

\section{Measurement}

A questionnaire consisting of 7 parts was used for collecting data from all subjects. The 7 parts of the questionnaire included questions on demographic characteristics, knowledge of palliative care (4 items), knowledge of provision of $\mathrm{ANH}$ for terminal cancer patients (17 items), attitudes (17 items), behavioral intentions (2 items), subjective norms (5 items), and influencing factors (13 items). The definition and status of "terminal cancer patient" as provided for the participants in this questionnaire were the following: "A patient with terminal stomach cancer is defined as a patient who had received surgery for stomach cancer (stage IIIb) 3 years prior; in whom pulmonary and abdominal metastases had been discovered 1 year prior; who had received chemotherapy for 6 months, which was ineffective and the patient had declined further chemotherapy; and who subsequently switched to folk medicine. The patient was presently admitted through the emergency department because of complaints of dyspnea and abdominal distention; examination results showed pleural and peritoneal effusions; and a predicted survival time of less than 1 month was determined by the attending physician.'

The questionnaire was tested for content validity by 4 physicians and 2 nurses, all of whom were experienced in the care of the terminally ill. Each item in the questionnaire was appraised from "very inappropriate and not relevant" (1) to "very appropriate and relevant" (5). A content validity index was used to determine the validity of the structured questionnaire and yielded a content validity index value of 0.93 . Demographic characteristics assessed by the questionnaire 
included sex, age, education, experience in caring for terminal cancer patients, and experience with ANH given to terminal cancer patients cared for in the past year. The other 6 parts included the following:

1. Knowledge of palliative care. The scoring system of this scale was "true" (1) and "false/unknown" (0). A KuderRichardson Formula 20 was used to assess the internal consistency of this knowledge measure and showed a coefficient of variation of 0.80 for 4 items.

2. Knowledge of the provision of ANH for terminal cancer patients. Reverse scoring was used in items $1-2,1-3,1-4$, $1-6,2-1,2-2,2-4,3-2,3-3,3-4,3-5$, and 3-7. The scoring system of this scale was "true" (1) and "false/unknown" (0). Total knowledge scores were ordered numerically for discrimination analysis. Nurses in the top $30 \%$ of scores and the bottom $30 \%$ of scores were designated as highand low-scoring groups, respectively. After analysis by independent sample $t$ test, 2 items of low discrimination were deleted (Table 1). Also, after determining the Pearson correlation between the total score and each item, the same 2 items were unrelated to the total score. In the final questionnaire, the Kuder-Richardson Formula 20 value was 0.68 for 15 items, indicating that internal consistency between items was acceptable.

3. Attitudes (belief and evaluation) about providing ANH for terminal cancer patients. This part examined the perception of nurses regarding the advantages and disadvantages of providing ANH for terminal cancer patients. The measure had 17 items scored using 5-point Likert scales, from "strongly disagree or very unimportant" (1) to "strongly agree or very important" (5). Reverse scoring was used in the advantages section regarding providing $\mathrm{ANH}$. A higher total attitude score indicated a more positive attitude of the nurse regarding provision of ANH for terminal cancer patients. Bartlett's test of sphericity and Kaiser-MeyerOlkin test were used to determine whether belief data were suitable for exploratory factor analysis. In this measure, the value of the Bartlett's test was 1,164.026, significant value was 0.000 , and the Kaiser-Meyer-Olkin value was 0.792 . Therefore, the measure was suitable for exploratory factor analysis. The draft items were analyzed using principal component analysis followed by orthogonal varimax rotation. The cut point of factor loading was set at 0.4. Finally, the beliefs measure was constructed as "benefits of providing ANH" (8 items) and "burdens of providing

Table 1 ${ }^{-}$Discrimination Analysis of Items $(N=197)^{a}$

\begin{tabular}{|c|c|c|}
\hline Labeling & Item & $t$ Value \\
\hline $1-1$ & $\begin{array}{l}\text { ANH includes nutritional replacement methods such as tube feeding (eg, nasogastric tube, gastrostomy, and } \\
\text { jejunostomy) and intravenous infusion. }\end{array}$ & -0.079 \\
\hline $1-2^{\mathrm{b}}$ & ANH replacement is beneficial for all terminally ill patients. & $9.865^{\mathrm{c}}$ \\
\hline $1-3^{\mathrm{b}}$ & ANH replacement can improve the strength of all terminally ill patients. & $8.955^{\mathrm{c}}$ \\
\hline $1-4^{\mathrm{b}}$ & ANH replacement is necessary in preventing dysphagic terminally ill patients from starving to death. & $6.656^{\mathrm{c}}$ \\
\hline $1-5$ & Artificial nutrition replacement can result in abnormal cell growth and tumor enlargement. & $3.787^{\mathrm{c}}$ \\
\hline $1-6^{\mathrm{b}}$ & ANH replacement signifies empathy and care for the patient from medical personnel or family members. & $7.001^{\mathrm{c}}$ \\
\hline $2-1^{b}$ & $\begin{array}{l}\text { Cachexia in terminal cancer patients clinically manifests as decreased protein synthesis and increased degradation, } \\
\text { decreased carbohydrate tolerance, and increased lipolysis; therefore, major nutritional support such as total } \\
\text { parenteral nutrition should be provided to replace the energy required for metabolism. }\end{array}$ & $8.397^{\mathrm{c}}$ \\
\hline $2-2^{\mathrm{b}}$ & $\begin{array}{l}\text { Tumor cell carbohydrate metabolism is mainly via lactic acid production from anaerobic metabolism and } \\
\text { increasing gluconeogenesis; therefore, major nutritional supplements should be given to reduce lactic acid } \\
\text { accumulation from anaerobic metabolism. }\end{array}$ & $5.359^{\mathrm{c}}$ \\
\hline $2-3$ & $\begin{array}{l}\text { In terminal cancer patients, because of abnormalities in carbohydrate, protein, and fat metabolism, even } \\
\text { aggressive nutritional support will not be able to improve patient nutritional status and weight. }\end{array}$ & $2.356^{\mathrm{d}}$ \\
\hline $2-4^{\mathrm{b}}$ & $\begin{array}{l}\text { In terminal cancer patients, chronic starvation results in lipolysis, with subsequent ketoacidosis and anorexia; } \\
\text { therefore, nutritional support such as nasogastric feeding should be provided to improve the malnutrition } \\
\text { resulting from anorexia. }\end{array}$ & $5.762^{\mathrm{c}}$ \\
\hline $3-1$ & Reduced oral intake ability in patients is a natural process in the progression to terminal state. & 0.519 \\
\hline $3-2^{\mathrm{b}}$ & The sensation of mouth dryness and thirst in terminally ill patients is mainly caused by dehydration. & $4.078^{\mathrm{c}}$ \\
\hline $3-3^{\mathrm{b}}$ & $\begin{array}{l}\text { Artificial hydration replacement can improve the sensation of mouth dryness and thirst in all terminally } \\
\text { ill patients. }\end{array}$ & $7.264^{\mathrm{c}}$ \\
\hline $3-4^{\mathrm{b}}$ & Terminally ill patients are often hungry from dysphagia and aphagia. & $5.950^{c}$ \\
\hline $3-5^{\mathrm{b}}$ & Artificial nutrition replacement can improve hunger status in all termin & $6.646^{\mathrm{c}}$ \\
\hline $3-6$ & $\begin{array}{l}\text { Aggressive nutritional support by tube feeding cannot change the nutritional status or weight of terminally } \\
\text { ill patients. }\end{array}$ & $5.814^{\mathrm{c}}$ \\
\hline $3-7^{\mathrm{b}}$ & Ketoacidosis as a consequence of aphagia often results in an increase in physical pain in terminally ill patients. & $3.463^{\mathrm{c}}$ \\
\hline
\end{tabular}

Abbreviation: $\mathrm{ANH}$, artificial nutrition and hydration.



${ }^{\mathrm{b}}$ Reverse scoring was used.

${ }^{\mathrm{c}} P<.001$.

${ }^{\mathrm{d}} P<.05$. 
ANH" (9 items). Cronbach $\alpha$ for these factors were .78 and .84 , respectively, showing that items contained in each factor could be used to test the same characteristic. Cronbach $\alpha$ for the overall questionnaire was .73.

4. Behavioral intentions. After the study, assuming that a higher total behavioral intentions score indicated a more positive behavioral intention in nurses providing $\mathrm{ANH}$ for terminal cancer patients, the scoring categories were "very unlikely" (4), "unlikely" (3), "likely" (2), and "very likely" (1). Cronbach $\alpha$ was .71 for 2 items.

5. Subjective norms. This part explored which persons influenced nurses' provision of ANH for terminal cancer patients. A 5-point Likert scale was used, from "very unimportant" (1) to "very important" (5).

6. Influencing factors. This part determined the factors influencing nurses toward provision of ANH for terminal cancer patients. A 5-point Likert scale was used, from "strongly disagree" (1) to "strongly agree" (5).

\section{Statistical Analysis}

All data were analyzed using the SPSS 11.0 statistical software. A frequency distribution was used to describe the demographic data and the distribution of each variable. Mean values and standard deviations were used to analyze the degree of each variable in the knowledge of palliative care and $\mathrm{ANH}$, beliefs and evaluations on the use of $\mathrm{ANH}$, and subjective norm measures. A $P$ value of less than .05 was considered significant.

\section{Results}

\section{Demographic Characteristics}

Nurse subjects were $98.5 \%$ women, with an average age of $30 \pm 6.3$ years. Of these, $69.5 \%$ were unmarried, and $69.1 \%$ had an education level of bachelor's degree or above. Religious preferences included $41.8 \%$ Buddhist and $40.7 \%$ with no declared religious preference ("none"). The number of nurses with fewer than 2 years' experience, between 2 and 5 years' experience, between 5 and 10 years' experience, and more than 10 years' experience each made up approximately one quarter of the total. Of 197 nurses, only 6 (3.1\%) did not have experience providing care for terminal cancer patients, and $57.4 \%$ of the nurses had never received in-service education about palliative care. Within the terminal cancer patients cared for by the nurses in the previous year, $80.6 \%$ had been given peripheral parenteral nutrition, $80.1 \%$ had received intravenous fluid replacement, $84.7 \%$ had used a nasogastric tube or nasojejunal tube feeding, and $73.0 \%$ had been given total parenteral nutrition (Table 2).

\section{Knowledge of Palliative Care}

Regarding knowledge of palliative care, the average score among nurses was 3.87 (SD, 0.42; range, 0-4), with a accurate-

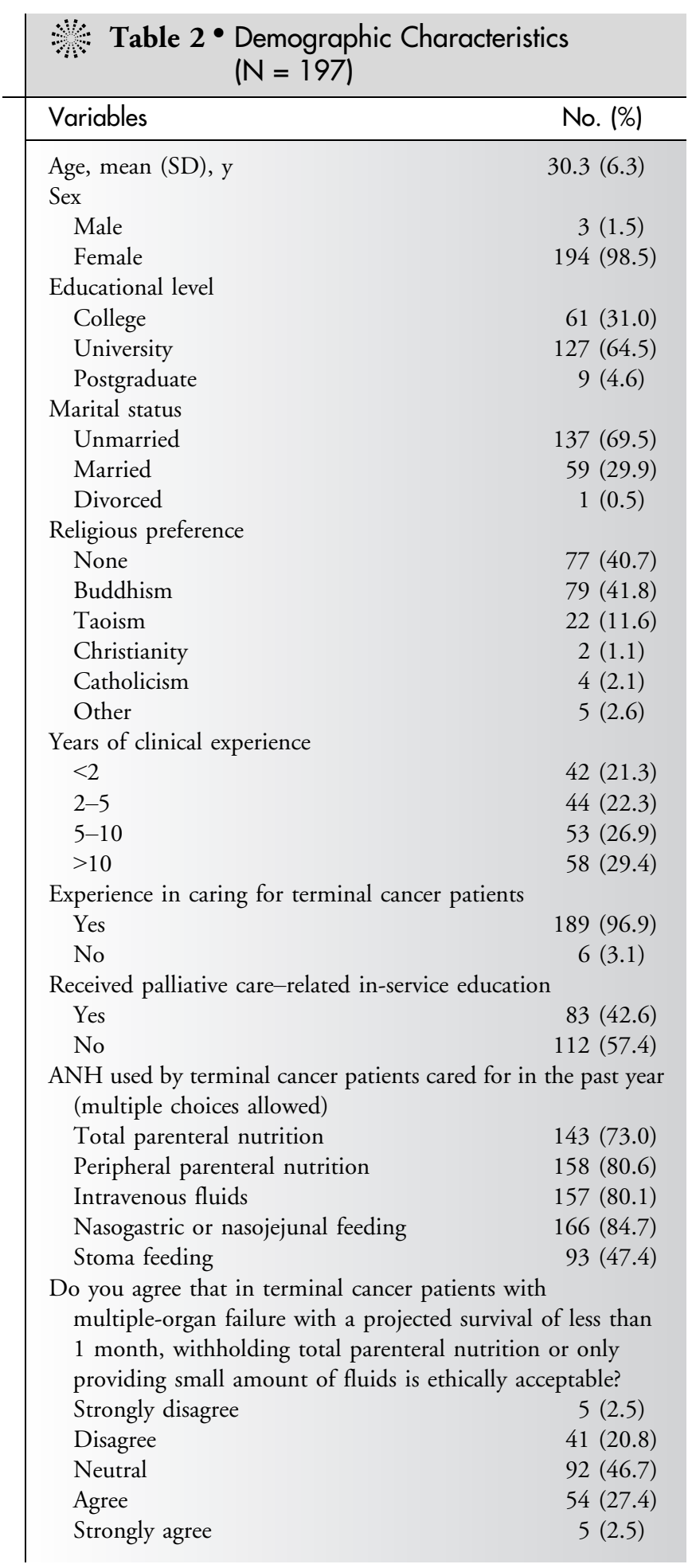

Abbreviation: $\mathrm{ANH}$, artificial nutrition and hydration.

answer rate of $96.75 \%$. Within this part, items receiving the highest accurate-answer rate were the following: "the main aim of palliative care is to raise the quality of life of terminally ill patients" (99.5\%), "in palliative care, appropriate consideration is given to the provision of necessary artificial hydration and artificial nutrition replacements based on the needs of terminally ill patients" (99.5\%), "palliative care respects the autonomy of terminally ill patients" (99.0\%), and 
"palliative care does not administer unnecessary tests or treatments" (89.3\%).

\section{Knowledge of Provision of ANH for Terminal Cancer Patients}

Regarding knowledge of provision of ANH for terminal cancer patients, the average score among nurses was 8.05 (SD, 2.96; range, 0-15), with a accurate-answer rate of $53.67 \%$. Only 1 item had a accurate-answer rate above $60 \%$; this item was "artificial nutrition replacement can improve hunger status in all terminally ill patients" (72.6\%). The second and third highest accurate-answer rates, respectively, were for the items "artificial hydration replacement can improve the sensation of mouth dryness and thirst in all terminally ill patients" (59.9\%) and "in terminal cancer patients, because of abnormalities in carbohydrate, protein, and fat metabolism, even aggressive nutritional support will not be able to improve patient nutritional status and weight" (56.9\%). The 3 lowest accurate scoring items were "ketoacidosis as a consequence of aphagia often results in an increase in physical pain in terminally ill patients" (9.6\%); "in terminal cancer patients, chronic starvation results in lipolysis, with subsequent ketoacidosis and anorexia; therefore, nutritional support such as nasogastric feeding should be provided to improve malnutrition resulting from anorexia" (18.3\%); and "cachexia in terminal cancer patients clinically manifests as decreased protein synthesis and increased degradation, decreased carbohydrate tolerance, and increased lipolysis; therefore, major nutritional support such as total parenteral nutrition should be provided to replace energy required for metabolism" (27.4\%) (Table 3). The above results reveal that nurses did not believe that ANH could improve hunger, thirst, and weight status of terminal cancer patients and that nurses had an inadequate understanding of energy metabolism in terminal cancer patients and the effects of $\mathrm{ANH}$ on physiological metabolism.

\section{Attitudes on Provision of ANH for Terminal Cancer Patients}

The total score among nurses for the "attitudes on provision of ANH for terminal cancer patients" part was 10.44 (SD, 2.06; range, 1-25).

Regarding the benefits of providing $\mathrm{ANH}$, the average score was 6.35 (SD, 2.19; range, 1-25). The highest scoring item was "it can prolong the life of terminally ill patients" (10.60). The 3 lowest scoring items were "correcting body fluid electrolytes is definitely beneficial for patient mental awareness" (4.99), "the provision of ANH lowers the anxiety of patients and their family members and also aids in developing trust from terminally ill patients and their family members" (5.41), and "it reduces the feeling of abandonment in terminally ill patients" (5.71). These scores showed that nurses seemed to disagree on the advantage of ANH in prolonging the life of terminally ill patients but still favored providing $\mathrm{ANH}$ as a gesture of psychological support for patients and their family members.

Regarding the burdens of providing $\mathrm{ANH}$, the average score was 14.12 (SD, 3.62; range, 1-25). The 3 highest scoring items were, respectively, "placement of invasive catheters increases the risk of infection in terminally ill patients" (16.02); "regarding terminally ill patients, fluid overload is likely to result in pleural effusion or pulmonary edema" (15.82); and "fluid overload can occur in terminally ill patients receiving intravenous infusions, such as ascites or peripheral edema" (15.64). Correspondingly, the 3 lowest scoring items were "in terminally ill patients, increased respiratory tract mucous production may result from intravenous infusions with subsequent need of suction" (11.10); "among medical treatments, total parenteral nutrition is a high-cost therapy" (12.79); and "invasive procedures, such as the placement of central venous catheters, cause pain in terminally ill patients" (12.99). The beliefs scale revealed that the degree of agreement between nurses on the disadvantages of ANH were all greater than 2.50, showing significant general consensus among nurses about the detrimental effects of ANH on terminally ill patients (Table 4).

\section{Behavioral Intentions on Provision of ANH for Terminal Cancer Patients}

The total score among nurses for the "behavioral intentions on provision of ANH for terminal cancer patients" part was 3.21 (SD, 0.95; range, 2-8). Ninety-eight percent of nurses were likely $(51.8 \%)$ or very likely (46.2\%) to provide artificial hydration for terminal cancer patients, and $98 \%$ of nurses were likely $(60.9 \%)$ or very likely $(37.1 \%)$ to provide artificial nutrition for terminal cancer patients (Table 5). Regarding behavioral intentions on the amount of fluid provided, $71.4 \%$ of nurses leaned toward providing terminal cancer patients with 1,000 $\mathrm{mL}$ or more artificial hydration daily (Table 6).

\section{Subjective Norms Influencing Provision of ANH for Terminal Cancer Patients by Nurses}

Results were the following: "attending physician or superiors," 4.06; "the patient," 4.02; "family members," 3.86; and "nurses," 3.65. Within these, $45.3 \%$ of nurses believed that "attending physician or superiors" were the most influential people, followed by "the patient" (38.4\% of nurses).

\section{Factors Influencing Provision of ANH for Terminal Cancer Patients by Nurses}

The resulting 5 highest scoring items were, respectively, "I believe that medical personnel have the duty of informing patients and their family members about disease progression and prognosis" (4.26); "I believe that the overall patient condition, such as age, site of tumor, predicted survival period, and oral intake ability, should be taken into account in the 


\begin{tabular}{|c|c|c|c|c|c|}
\hline Labeling & Item (Scoring Range for Each Item Is 0-1 Points) & $\begin{array}{l}\text { Answered } \\
\text { Correctly, } \\
\text { No. (\%) }\end{array}$ & $\begin{array}{l}\text { Answered } \\
\text { Incorrectly, } \\
\text { No. (\%) }\end{array}$ & $\begin{array}{l}\text { Not } \\
\text { Clear, } \\
\text { No. }(\%)\end{array}$ & Ranking \\
\hline \multicolumn{6}{|c|}{ A. About the administration and treatment aims of $\mathrm{ANH}$} \\
\hline 1 & ANH replacement is beneficial for all terminally ill patients. & $95(48.2)$ & $90(45.7)$ & $12(6.1)$ & 7 \\
\hline 2 & ANH replacement can improve the strength of all terminally ill patients. & $69(35.0)$ & $116(58.9)$ & $12(6.1)$ & 10 \\
\hline 3 & $\begin{array}{l}\text { ANH replacement is necessary in preventing dysphagic terminally ill } \\
\text { patients from starving to death. }\end{array}$ & $75(38.1)$ & $111(56.3)$ & $11(5.6)$ & 8 \\
\hline 4 & $\begin{array}{l}\text { Artificial nutrition replacement can result in abnormal cell growth and } \\
\text { tumor enlargement. }\end{array}$ & $110(55.8)$ & $50(25.4)$ & $37(18.8)$ & 4 \\
\hline 5 & $\begin{array}{l}\text { ANH replacement signifies empathy and care for the patient from medical } \\
\text { personnel and family members. }\end{array}$ & $105(53.3)$ & $80(40.6)$ & $12(6.1)$ & 6 \\
\hline \multicolumn{6}{|c|}{ B. Physiological metabolism of terminal cancer patients and nutrition provision } \\
\hline 1 & $\begin{array}{l}\text { Cachexia in terminal cancer patients clinically manifests as decreased protein } \\
\text { synthesis and increased degradation, decreased carbohydrate tolerance, } \\
\text { and increased lipolysis; therefore, major nutritional support such as total } \\
\text { parenteral nutrition should be provided to replace the energy required for } \\
\text { metabolism. }\end{array}$ & $54(27.4)$ & $130(66.0)$ & $13(6.6)$ & 13 \\
\hline 2 & $\begin{array}{l}\text { Tumor cell carbohydrate metabolism is mainly via lactic acid production } \\
\text { from anaerobic metabolism and increasing gluconeogenesis; therefore, } \\
\text { major nutritional supplements should be given to reduce lactic acid } \\
\text { accumulation from anaerobic metabolism. }\end{array}$ & $60(30.5)$ & $93(47.2)$ & $44(22.3)$ & 11 \\
\hline 3 & $\begin{array}{l}\text { In terminal cancer patients, because of abnormalities in carbohydrate, } \\
\text { protein, and fat metabolism, even aggressive nutritional support will not } \\
\text { be able to improve patient nutritional status and weight. }\end{array}$ & $112(56.9)$ & $70(35.5)$ & $15(7.6)$ & 3 \\
\hline 4 & $\begin{array}{l}\text { In terminal cancer patients, chronic starvation results in lipolysis, with } \\
\text { subsequent ketoacidosis and anorexia; therefore, nutritional support such } \\
\text { as nasogastric feeding should be provided to improve malnutrition } \\
\text { resulting from anorexia. }\end{array}$ & $36(18.3)$ & $138(70.1)$ & $23(11.7)$ & 14 \\
\hline \multicolumn{6}{|c|}{ C. Links between terminally ill patients with dehydration, hunger, and comfort } \\
\hline 1 & $\begin{array}{l}\text { The sensation of mouth dryness and thirst in terminally ill patients is mainly } \\
\text { caused by dehydration. }\end{array}$ & $58(29.4)$ & $115(58.4)$ & $24(12.2)$ & 12 \\
\hline 2 & $\begin{array}{l}\text { Artificial hydration can improve the sensation of mouth dryness and thirst in } \\
\text { all terminally ill patients. }\end{array}$ & $118(59.9)$ & $69(35.0)$ & $10(5.1)$ & 2 \\
\hline 3 & Terminally ill patients are often hungry from dysphagia and aphagia. & $70(35.5)$ & $105(53.3)$ & $22(11.2)$ & 9 \\
\hline 4 & $\begin{array}{l}\text { Artificial nutrition replacement can improve hunger status in all terminally } \\
\text { ill patients. }\end{array}$ & $143(72.6)$ & $38(19.3)$ & $16(8.1)$ & 1 \\
\hline 5 & $\begin{array}{l}\text { Aggressive nutritional support by tube feeding cannot change the nutritional } \\
\text { status or weight of terminally ill patients. }\end{array}$ & $109(55.3)$ & $71(36.0)$ & $17(8.6)$ & 5 \\
\hline 6 & $\begin{array}{l}\text { Ketoacidosis as a consequence of aphagia often results in an increase in } \\
\text { physical pain in terminally ill patients. } \\
\text { Average total knowledge score }=8.05(\mathrm{SD}, 2.96)\end{array}$ & $19(9.6)$ & $124(62.9)$ & $54(27.4)$ & 15 \\
\hline
\end{tabular}

Abbreviation: ANH, artificial nutrition and hydration.

provision of ANH" (4.20); "I believe that medical personnel have the duty of informing patients and their family members about the advantages and disadvantages of $\mathrm{ANH}$, with the patient or their family members deciding whether it should be provided" (4.17); "I believe that terminally ill patients have the right to refuse administration of $\mathrm{ANH}^{\circ}$ (3.98); and "I believe that ANH replacement should take into account the will of terminally ill patients" (3.93). These results showed that nurses believed that patient autonomy should be respected in the provision of ANH.

However, in practical clinical practice, nurses are influenced by many factors, including the following: "I believe that the opinions of physician colleagues are important to me"
(3.83), "I believe that the opinions of nursing colleagues are important to me" (3.83), "I believe that the provision of food and water constitutes the most basic care for terminally ill patients" (3.80), "I believe that letting terminally ill patients die in a dehydrated state is ethically unacceptable" (3.77), "I am worried that refusing to provide ANH for terminally ill patients will result in medical dispute" (3.42), "I believe that refusal to provide ANH is difficult to communicate to patients or their families" (3.40), and "I believe that colleague opinions are divided on whether ANH should be provided" (3.01). These results showed that factors influencing the provision of ANH for terminal cancer patients by nurses included factors such as judgments made from ethical reasoning, fear of 


\begin{tabular}{|c|c|c|c|c|c|}
\hline Labeling & Item (Scoring Range for Each Item Is $1-5$ Points) & $\begin{array}{l}\text { Beliefs }\left(B_{i}\right) \\
\text { mean }(S D)\end{array}$ & $\begin{array}{l}\text { Evaluations }\left(E_{i}\right) \\
\text { mean }(S D)\end{array}$ & $\begin{array}{l}\text { Attitude }\left(B_{i} \times E_{i}\right) \\
\quad \text { mean }(S D)\end{array}$ & Ranking \\
\hline \multicolumn{2}{|c|}{ A. Benefits of providing $\mathrm{ANH}$} & $2.46(0.51)$ & $2.40(0.46)$ & $6.35(2.19)$ & \\
\hline $1^{\mathrm{a}}$ & $\begin{array}{l}\text { It can reduce dehydration-induced delirium in terminally } \\
\text { ill patients. }\end{array}$ & $2.34(0.64)$ & $2.36(0.64)$ & $5.71(2.71)$ & 5 \\
\hline $2^{\mathrm{a}}$ & $\begin{array}{l}\text { Correcting body fluid electrolytes is definitely beneficial } \\
\text { for patient mental awareness. }\end{array}$ & $2.18(0.75)$ & $2.15(0.69)$ & $4.99(2.91)$ & 8 \\
\hline $3^{\mathrm{a}}$ & It can prolong the life of terminally ill patients. & $3.31(0.92)$ & $3.07(0.82)$ & $10.60(5.02)$ & 1 \\
\hline $4^{\mathrm{a}}$ & $\begin{array}{l}\text { It reduces the feeling of abandonment in terminally } \\
\text { ill patients. }\end{array}$ & $2.36(0.88)$ & $2.26(0.74)$ & $5.71(3.48)$ & 6 \\
\hline $5^{a}$ & $\begin{array}{l}\text { It improves mouth dryness and thirst in terminally } \\
\text { ill patients. }\end{array}$ & $2.46(0.77)$ & $2.42(0.72)$ & $6.32(3.64)$ & 2 \\
\hline $6^{\mathrm{a}}$ & $\begin{array}{l}\text { The provision of ANH lowers the anxiety of patients and } \\
\text { their family members and also aids in developing trust } \\
\text { from terminally ill patients and their family members. }\end{array}$ & $2.30(0.74)$ & $2.25(0.69)$ & $5.41(2.92)$ & 7 \\
\hline $7^{\mathrm{a}}$ & $\begin{array}{l}\text { By providing ANH, family members can express their care } \\
\text { for terminally ill patients. }\end{array}$ & $2.35(0.84)$ & $2.35(0.74)$ & $5.96(3.45)$ & 3 \\
\hline $8^{\mathrm{a}}$ & $\begin{array}{l}\text { Providing ANH can prevent despair from worsening in } \\
\text { terminally ill patients. }\end{array}$ & $2.37(0.87)$ & $2.31(0.77)$ & $5.93(3.60)$ & 4 \\
\hline \multicolumn{2}{|c|}{ B. Burdens of providing ANH } & $3.69(0.56)$ & $3.70(0.54)$ & $14.12(3.62)$ & \\
\hline 1 & $\begin{array}{l}\text { As a medical treatment, total parenteral nutrition is a } \\
\text { high-cost therapy. }\end{array}$ & $3.62(0.86)$ & $3.43(0.80)$ & $12.79(5.04)$ & 8 \\
\hline 2 & $\begin{array}{l}\text { Invasive procedures, such as the placement of central venous } \\
\text { catheters, cause pain in terminally ill patients. }\end{array}$ & $3.54(0.92)$ & $3.55(0.83)$ & $12.99(5.43)$ & 7 \\
\hline 3 & $\begin{array}{l}\text { Placement of invasive catheters increases the risk of infection } \\
\text { in terminally ill patients. }\end{array}$ & $4.04(0.78)$ & $3.87(0.80)$ & $16.02(5.33)$ & 1 \\
\hline 4 & $\begin{array}{l}\text { Activities of terminally ill patients are restricted by } \\
\text { in-dwelling tubing. }\end{array}$ & $3.68(0.92)$ & $3.69(0.81)$ & $14.04(5.67)$ & 6 \\
\hline 5 & $\begin{array}{l}\text { High-energy supplements via central venous infusion can } \\
\text { induce septicemia in terminally ill patients. }\end{array}$ & $3.72(0.79)$ & $3.75(0.76)$ & $14.36(5.21)$ & 5 \\
\hline 6 & $\begin{array}{l}\text { Nausea and vomiting can occur in terminally ill patients } \\
\text { because of increased digestive tract secretions. }\end{array}$ & $3.74(0.73)$ & $3.78(0.72)$ & $14.49(4.69)$ & 4 \\
\hline 7 & $\begin{array}{l}\text { Fluid overload, such as ascites or peripheral edema, can occur } \\
\text { in terminally ill patients receiving intravenous infusions. }\end{array}$ & $3.88(0.84)$ & $3.91(0.80)$ & $15.64(5.63)$ & 3 \\
\hline 8 & $\begin{array}{l}\text { In terminally ill patients, increased respiratory tract mucous } \\
\text { production may result from intravenous infusions with } \\
\text { subsequent need of suction. }\end{array}$ & $3.08(1.07)$ & $3.44(0.92)$ & $11.10(5.78)$ & 9 \\
\hline 9 & $\begin{array}{l}\text { In terminally ill patients, fluid overload is likely to result } \\
\text { in pleural effusion or pulmonary edema. }\end{array}$ & $3.94(0.78)$ & $3.91(0.80)$ & $15.82(5.36)$ & 2 \\
\hline
\end{tabular}

Abbreviation: ANH, artificial nutrition and hydration.

${ }^{a}$ Total attitude scoring range $=1-25$ points. A higher total attitude score indicates a positive attitude of leaning toward not providing ANH for terminal cancer patients.

${ }^{b}$ Reverse scoring was used.

medical dispute, and also concerns about communication with the treatment team, the patients, and their family members.

\section{Discussion}

To our knowledge, this study is one of the first to investigate the behavioral intentions of nursing staff toward providing ANH for terminal cancer patients, particularly in the Asia Pacific region. Study results revealed that nurses have a sufficient understanding of palliative care, but knowledge of the provision of ANH for terminal cancer patients still seems to be inadequate. Most notably, nurses have an inadequate understanding of energy metabolism in terminal cancer patients and the effects of ANH on physiological metabolism, while also holding misconceptions such as "ANH prevents starvation and improves strength in terminally ill patients." This was similar to study results obtained by Chiu et $\mathrm{al}^{2}$ on patients in palliative care wards and their family members. This study showed that nurses have inadequate knowledge in even more dire situations involving patients and their family members. The reason behind these results is very likely a deficiency in knowledge among nurses regarding the usage of ANH in terminal cancer patients; hence, even though nurses understand palliative care, they have insufficient knowledge to make appropriate decisions in clinical medicine. It has been shown 
Table $5^{\bullet}$ Behavioral Intentions of Nurses on Provision of ANH for Terminal Cancer Patients $(\mathrm{N}=197)^{a}$

\begin{tabular}{|c|c|c|c|c|c|c|c|}
\hline Labeling & $\begin{array}{l}\text { Item (Scoring Range for } \\
\text { Each Item Is } 1-4 \text { Points) }\end{array}$ & $\begin{array}{l}\text { Never, } \\
\text { No. (\%) }\end{array}$ & $\begin{array}{l}\text { Unlikely, } \\
\text { No. (\%) }\end{array}$ & $\begin{array}{l}\text { Likely, } \\
\text { No. (\%) }\end{array}$ & $\begin{array}{c}\text { Very Likely, } \\
\text { No. (\%) }\end{array}$ & $\begin{array}{l}\text { Mean } \\
\text { (SD) }\end{array}$ & Ranking \\
\hline 1 & $\begin{array}{l}\text { In terminal stomach cancer patients who } \\
\text { cannot be fed orally because of intestinal } \\
\text { obstruction, and who have a projected } \\
\text { survival time of less than } 1 \text { month, will } \\
\text { I provide intravenous fluids? }\end{array}$ & $1(0.5)$ & $3(1.5)$ & $102(51.8)$ & $91(46.2)$ & $1.56(0.56)$ & 2 \\
\hline 2 & $\begin{array}{l}\text { In terminal gastric patients who cannot be } \\
\text { fed orally, what is the likelihood that I will } \\
\text { provide artificial nutrition? }\end{array}$ & $0(0.0)$ & $4(2.0)$ & $120(60.9)$ & $73(37.1)$ & $1.65(0.52)$ & 1 \\
\hline
\end{tabular}

Abbreviation: ANH, artificial nutrition and hydration.

${ }^{a}$ Total behavioral intention scoring range $=2-8$ points. A higher total behavioral intention score indicates a positive behavioral intention of leaning toward not providing $\mathrm{ANH}$ for terminal cancer patients.

that knowledge affects moral convictions and that sufficient theoretical knowledge is a necessary prerequisite in making ethical decisions. ${ }^{12}$ Therefore, nurse in-service education on this area should be strengthened to increase the confidence and ability of nurses and provide a basis for making competent ethical decisions in clinical practice.

The results of this study showed that nurses have a negative attitude toward providing ANH for terminal cancer patients, although still tending to provide ANH for terminal cancer patients. After analyzing their reasons, it was found that even though nurses disagreed on the benefit of ANH in "prolonging patient life," they agreed that ANH had the burdens mentioned in this study, especially items such as "placement of invasive catheters increases the risk of infection in terminally ill patients;" "in terminally ill patients, fluid overload is likely to result in pleural effusion or pulmonary edema;" and "fluid overload, such as ascites or peripheral edema, can occur in terminally ill patients receiving intravenous infusions." They also agreed on these items: "correcting body fluid electrolytes is definitely beneficial for patient mental awareness," "provision of ANH lowers the anxiety of patients and their family members and also aids in developing trust from terminally ill patients and their family members," and "it reduces the feeling of abandonment in terminally ill patients." The results of this study were similar to the results of a Japanese study focusing on physicians, which showed that medical personnel still leaned toward providing ANH for terminal cancer patients. ${ }^{3}$ However, even though nurses understand that terminal patients do not feel thirst, they are aware that dehydration may decrease suffering in the last days of patients' lives. In this situation of direct patient care and concentrated contact with patients, nurses are concerned that patients will be uncomfortable, and they may even fear losing the patient. ${ }^{6,21,24}$ Consequently, although nurses agree that providing ANH for terminal cancer patients has more burdens than benefits, they still continue to provide terminal cancer patients with ANH. This contradictory situation was also mentioned in the study by Solomon et al, ${ }^{10}$ in which $48 \%$ of medical personnel believed that "the burdens of continuing nutrition and hydration to a terminally ill patient can outweigh the benefits of prolonging life." However, $42 \%$ of medical personnel also agreed that "even if life support such as mechanical ventilation and dialysis are stopped, food and water should always be continued." Correspondingly, overseas and local research showed that the idea of "there are more burdens than benefits in the continual provision of ANH for terminal cancer patients" should be reinforced in medical personnel. To address this issue, ethical reasoning skills should be reinforced through in-service education, and multidisciplinary discussion of ethical issues should be encouraged.

\section{Table $6^{\bullet}$ Behavioral Intentions of Nurses on the Volume of Artificial Hydration Provided for Terminal Cancer Patients ( $N=197)$}

\begin{tabular}{|c|c|c|c|}
\hline Labeling & Variable & No. (\%) & Ranking \\
\hline 1 & $\begin{array}{l}\text { In terminal stomach cancer patients who cannot be fed orally because of } \\
\text { survival time of less than } 1 \text { month, will I provide intravenous fluids? } \\
\text { People who are "never" or "unlikely" to provide intravenous fluids } \\
\text { People who are "likely" or "very likely" to provide intravenous fluids } \\
\quad<500 \mathrm{~mL} \text { intravenous fluids daily } \\
\text { Between } 500 \text { and } 1,000 \mathrm{~mL} \text { intravenous fluids daily } \\
\text { Between } 1,000 \text { and } 1,500 \mathrm{~mL} \text { intravenous fluids daily } \\
\text { Between } 1,500 \text { and } 2,000 \mathrm{~mL} \text { intravenous fluids daily } \\
>2,000 \mathrm{~mL} \text { intravenous fluids daily }\end{array}$ & $\begin{array}{l}\text { ruction, an } \\
\qquad \begin{aligned} & (2.1) \\
188 & (97.9) \\
3 & (1.6) \\
48 & (25.0) \\
94 & (49.0) \\
37 & (19.3) \\
6 & (3.1)\end{aligned}\end{array}$ & $\begin{array}{l}5 \\
2 \\
1 \\
3 \\
4\end{array}$ \\
\hline
\end{tabular}


The behavioral intentions of nurses on the provision of ANH for terminal cancer patients leaned toward negative, indicating that nurses will provide ANH for terminal cancer patients. The results of this study showed that $71.4 \%$ of nurses favored providing terminal cancer patients with $1,000 \mathrm{~mL}$ or more artificial hydration daily, which is conservative when compared with the study results of Morita et $\mathrm{al}^{3}$ in which $80.8 \%$ of physicians believed that $1,000 \mathrm{~mL}$ or more artificial hydration should be provided daily for terminally ill patients. The reason for this disparity is possibly caused by differences in education between medical care personnel, with a nursing education promoting a more patient-centered thought pattern, focusing on care, and an MD medical education directed more by disease, focusing on cure. Subsequently, in clinical practice, nurses seemed more able to appreciate the discomfort of terminal cancer patients resulting from administration of $\mathrm{ANH}$ and favored providing terminal cancer patients with reduced amounts of artificial hydration.

Nearly half of the nurse subjects held a neutral view on "do you agree that in terminal cancer patients with multiple organ failure, with a projected survival of less than 1 month, withholding total parenteral nutrition or only providing small amounts of fluids is ethically acceptable?" (Table 2). When combined with "attending physician or superiors" as the most important persons influencing the provision of ANH for terminal cancer patients by nurses, this result was similar to the view of Wurzbach, ${ }^{12}$ whose study showed that nurses who have been moderately morally convinced to act upon personal choices and beliefs nevertheless professionally followed agency policies or physician's orders. It also highlights the fact that physicians are still the primary medical decision makers in clinical teams, with the result that even though clinical nurses understand and care about the needs of patients, they are constrained by a personal lack of knowledge. Consequently, they are unable to make appropriate clinical decisions and are restricted by the physician's authority and nurses' duty to follow medical orders, leaning toward the continual provision of ANH.

To summarize, study results show that nurses believe that the overall condition of patients should be taken into account in the provision of $\mathrm{ANH}$, and they also have the responsibility and obligation to inform patients and their family members about the benefits and burdens of $\mathrm{ANH}$, while at the same time respecting the psychosocial needs and autonomy of patients. However, because of insufficient knowledge and of misconceptions about ANH provision for patients, the influence of physicians, patient family members, and other colleagues on nurses in the overall medical system, compounded with fears of medical dispute, communication problems with patients, family members, and treatment staff, and the cultural influence of "food comes first for people," nurses are led to believe that providing ANH for terminally ill patients is the most basic care, and refusal to provide ANH is ethically unacceptable. In the end, patient autonomy is overlooked because the psychological and social needs of patients cannot be adequately addressed, and physiological needs are used instead to judge whether ANH should be provided for terminally ill patients.
The European Association for Palliative Care produced "Guidelines on Artificial Nutrition Versus Hydration in Terminal Cancer Patients" 29 as a reference for medical personnel. It emphasizes 3 steps: (1) assessment of the terminal cancer patient's oncological/clinical condition, symptoms, expected length of survival, hydration and nutritional status, spontaneous or voluntary nutrient intake, psychological attitude, gut function and the potential route of administration, and need for special services based on type of nutritional support prescribed; (2) overall assessment of the beneficial and detrimental effects that ANH has on the patient, to reach an appropriate decision after weighing all advantages and disadvantages; and (3) continual reevaluation regardless of whether ANH is provided for the terminal cancer patient. Only by repeated applications of the above-described steps, thorough discussions with the patient, and respecting a patient's will and autonomy can ANH be suitably provided for terminal cancer patients. Therefore, via in-service education and courses on ethical reasoning, it is hoped that nurses will be better equipped with critical reasoning ability and the moral strength needed in communicating with members of the treatment team to fully perform their role in providing terminal cancer patients with appropriate care at the most appropriate time.

\section{ACKNOWLEDGMENTS}

The authors thank the nursing staff of gastroenterology, general surgery, and intensive care unit of Taipei Veterans General Hospital for their full support.

\section{References}

1. Department of Health, Executive Yuan, Taiwan, ROC. 2004 Statistical Summary of the Main Causes of Death in Taiwan. http://www.doh. gov.tw/statistic/data/abstract of death reason/table1.xls. Accessed April 9, 2006.

2. Chiu TY, Hu WY, Chuang RB, et al. Terminal cancer patients' wishes and influencing factors toward the provision of artificial nutrition and hydration in Taiwan. J Pain Symptom Manage. 2004;27(3):206-214.

3. Morita T, Shima Y, Adachi I. Attitudes of Japanese physicians toward terminal dehydration: a nationwide survey. J Clin Oncol. 2002;20(24): 4699-4704.

4. Bruera E, Franco JJ, Maltoni M, et al. Changing pattern of agitated impaired mental status in patients with advanced cancer: association with cognitive monitoring, hydration, and opioid rotation. J Pain Symptom Manage. 1995;10(4):287-291.

5. Fainsinger RL, Bruera E, Miller MJ, et al. Symptom control during the last week of life on a palliative care unit. J Palliat Care. 1991;7(1):5-11.

6. Andrews MR, Levine AM. Dehydration in the terminal patient: perception of hospice nurses. Am J Hosp Care. 1989;6(1):31-34.

7. Day L, Drought T, Davis AJ. Principle-based ethics and nurses' attitudes towards artificial feeding. J Adv Nurs. 1995;21(2):295-298.

8. Musgrave CF, Bartal N, Opstad J. Intravenous hydration for terminal patients: what are the attitudes of Israeli terminal patients, their families, and their health professionals? J Pain Symptom Manage. 1996;12(1): 47-51.

9. Parkash R, Burge F. The family's perspective on issues of hydration in terminal care. J Palliat Care. 1997;13(4):23-27.

10. Solomon MZ, O'Donnell L, Jennings B, et al. Decisions near the end of life: professional views on life-sustaining treatments. Am J Public Health. 1993;83(1):14-23. 
11. Weissman DE, Ambuel B, Norton AJ, et al. A survey of competencies and concerns in end-of-life care for physician trainees. J Pain Symptom Manage. 1998;15(2):82-90.

12. Wurzbach ME. Long-term care nurses' moral convictions. J Adv Nurs. 1995;21(6):1059-1064.

13. Morita $T$, Tsunoda J, Inoue $S$, et al. Perceptions and decision-marking on rehydration of terminally ill cancer patients and family members. Am J Hosp Palliat Care. 1999;16(3):509-516.

14. MacDonald N, Fainsinger R. Indications and ethical considerations in the hydration of patients with advanced cancer. In: Bruera E, Higginson I, eds. Cachexia-Anorexia in Cancer Patients. New York, NY: Oxford University Press; 1996;94-110.

15. Musgrave CF. Terminal dehydration. To give or not to give intravenous fluids? Cancer Nurs. 1990;13(1):62-66.

16. Hughes N, Neal RD. Adults with terminal illness: a literature review of their needs and wishes for food. J Adv Nurs. 2000;32(5):1101-1107.

17. Mion LC, O'Connell A. Parenteral hydration and nutrition in the geriatric patient: clinical and ethical issues. J Infus Nurs. 2003;26(3): 144-152.

18. Micetich KC, Steinecker PH, Thomasma DC. Are intravenous fluids morally required for a dying patient? Arch Intern Med. 1983;143(5): 975-978.
19. Printz LA. Is withholding hydration a valid comfort measure in the terminally ill? Geriatrics. 1988;43(11):84-88.

20. Printz LA. Terminal dehydration, a compassionate treatment. Arch Intern Med. 1992;152(4):697-700.

21. Smith SA, Andrews M. Artificial nutrition and hydration at the end of life. Medsurg Nurs. 2000;9(5):233-247.

22. White KS, Hall JC. Ethical dilemmas in artificial nutrition and hydration: decision-making. Nurs Case Manag. 1999;4(3):152-157.

23. Zerwekh JV. The dehydration question. Nursing. 1983;13(1):47-51.

24. Zerwekh JV. Do dying patients really need IV fluids? Am J Nurs. 1997; 97(3):26-30.

25. Morita T, Tei $Y$, Inoue $S$, et al. Fluid status of terminally ill cancer patients with intestinal obstruction: an exploratory observational study. Support Care Cancer. 2002;10(6):474-479.

26. Burge FI, King DB, Willison D. Intravenous fluids and the hospitalized dying: a medical last rite? Can Fam Physician. 1990;36(5):883-886.

27. World Health Organization. Cancer Pain Relief and Palliative Care [Report of a WHO Expert Committee Geneva]. Geneva: WHO; 1990.

28. Lai YL. Hospice palliative care in Taiwan. Formosan J Med. 2004;8: 653-656.

29. Bozzetti F. Guidelines on artificial nutrition versus hydration in terminal cancer patients. Nutrition. 1996;12(3):163-167. 